\title{
Journal of Nephrology Research
}

\section{Analysis of Depression Among Adult Indian Peritoneal Dialysis Patients}

\author{
Arshi Rizwan, Sandeep Mahajan
}

Arshi Rizwan, Department of Microbiology, All India Institute of Medical Sciences, New Delhi 110029, India

Sandeep Mahajan, Department of Nephrology, All India Institute of Medical Sciences, New Delhi 110029, India

Corresponding Author: Dr. Sandeep Mahajan, Professor, Department of Nephrology, All India Institute of Medical Sciences, New Delhi 110029, India.

Email: mahajansn@yahoo.com

Telephone: +91-11-26491806

Received: Januray 14, 2016

Fax: $+91-11-26588663$

Accepted: March 12, 2016

Published online: April 7, 2016

\section{ABSTRACT}

AIM: Depression has recently been recognized as a highly prevalent, treatable condition among dialysis patients, which adversely affects their outcome. The incidence of depression among dialysis patients is reported to be around $25-50 \%$ in various western studies. In the few studies that have looked at depression among the chronic peritoneal dialysis (PD) patients, depression has been variously linked with; adverse patient outcome, higher incidence of peritonitis and poor nutritional status. Only a few studies have looked at the socioeconomic and medical factors associated with depression among these patients, especially from our sub-continent. The present study was therefore undertaken to look at; the prevalence of depression, factors associated with depression among Indian PD patients.

MATERIALS AND METHODS: All consenting patients on PD for $\geqslant 6$ months were administered Beck Depression Inventory (BDI) to screen for depression. Depression was classified on BDI scores as borderline to moderate (score $\geqslant 17$ ) and severe (score $>30$ ). Patients demographic, medical and co-morbidity profile was also recorded. RESULTS: 82 patients were administered BDI (mean PD duration, $47.6 \pm 21.1$ months). $50(61 \%)$ had depression (BDI scores 17$30)$, while $12.2 \%(n=10)$ had severe depression (BDI scores $>$ 30). On multivariate regression analysis we found that depressed patients had lower blood urea, serum alkaline phosphatase and serum albumin. Residual renal function, duration of peritoneal dialysis and presence of diabetes and other co-morbid conditions did not correlate significantly with depression.

CONCLUSION: We document a high prevalence of depression among Indian PD patients. Depressed patients had evidence of poor dietary protein intake and poorer nutrition as evidenced by lower serum urea and albumin. Further studies looking at effect of early detection and treatment of depression on PD outcome are warranted.

\section{2016 The Authors. Published by ACT Publishing Group Ltd.}

Key words: Beck depression inventory; Serum albumin; Nutritional markers

Rizwan A, Mahajan S. Analysis of Depression Among Adult Indian Peritoneal Dialysis Patients. Journal of Nephrology Research 2016; 2(1): 109-112 Available from: URL: http://www.ghrnet.org/index.php/ jnr/article/view/1570

\section{INTRODUCTION}

With the increasing incidence and prevalence of end stage renal disease (ESRD) search for factors that are amenable to therapy and which adversely affect patient outcome and quality of life (QOL) is gathering momentum. This has brought forth in focus psychosocial factors among ESRD patients ${ }^{[1-3]}$. Depression is recognized as the most common psychological problem encountered among patients with ESRD $^{[1-4]}$. Studies have suggested that depressive symptoms occur in $25-50 \%$ of patients maintained on dialysis therapy ${ }^{[2,3,5]}$. The studies looking at depression among dialysis patients are mainly from the United States and Europe and have been performed predominantly among HD patients. Few studies among patients on chronic peritoneal dialysis (PD) have correlated depression with poor patient survival and increased risk of peritonitis ${ }^{[6,7]}$. Race and geographical area have been shown to be important factors affecting 


\begin{tabular}{ll}
\hline \multicolumn{2}{l}{ Table 1 Baseline characteristics of study population } \\
\hline Characteristic & No (82) \\
\hline Mean BDI score & $19.1 \pm 7.9$ \\
\hline Age (years) & $51.5 \pm 11.5$ \\
Male (\%) & $53(64.6)$ \\
Female (\%) & $29(35.3)$ \\
\hline Literacy Status (\%) & \\
\hline Illiterate & $31(37.8)$ \\
\hline Higher secondary & $12(14.6)$ \\
Graduate & $28(34.1)$ \\
Post-graduate & $11(13.4)$ \\
\hline Presence of Diabetes (\%) & $28(34.1)$ \\
\hline Duration of PD (months) & $47.6 \pm 21.1$ \\
Coronary artery disease (\%) & $17(20.7)$ \\
\hline Body Mass Index & $22.7 \pm 4.2$ \\
Urine output (ml/day) & $710.8 \pm 211.6$ \\
\hline Hemoglobin (gm/dl) & $9.1 \pm 0.9$ \\
\hline Blood Urea (mg/dl) & $113.2 \pm 22.6$ \\
Serum Creatinine (mg/dl) & $6.4 \pm 0.7$ \\
Serum Alkaline Phosphatase (IU/dl) & $179 \pm 0.60$ \\
Total Protien (gm/dl) & $6.6 \pm 0.2$ \\
Serum Albumin (gm/dl) & $3.5 \pm 0.30$ \\
\hline Serum Cholesterol (mg/dl) & $166.5 \pm 35.4$ \\
Serum LDL/HDL Ratio & $2.6 \pm 0.4$ \\
Calcium (mg/dl) & $8.3 \pm 0.5$ \\
\hline Phosphate (mg/dl) & $4.9 \pm 0.9$ \\
\hline Uric acid (mg/dl) & $5.1 \pm 1.1$ \\
\hline
\end{tabular}

depression among ESRD patients ${ }^{[4]}$. In a study from Korea, the prevalence of depression among PD patients was found to be $75 \%{ }^{[8]}$ as opposed to $33-50 \%$ reported from western studies ${ }^{[6,7]}$. Also, only a few studies have looked at the socio-economic and medical factors associated with depression in these patients. Identifying these factors can help in determining the patients who are at a higher risk of developing depressive symptoms. The present study was therefore undertaken to look at; the prevalence of depression among Indian PD patients and the factors associated with depression.

\section{MATERIALS AND METHODS}

All patients on PD for $\geqslant 6$ months, who consented for screening for depression, were enrolled. Beck Depression Inventory (BDI) was used to screen the patients. The BDI is a 21 -item self-report rating inventory measuring characteristic attitudes and symptoms of depression. The 21 items are answered on 4 point Likert scale in which zero represents the absence of problem and 3 represents an extreme problem with a total ranging from $0-63$. The patients were classified as being normal (BDI score $\leqslant 10$ ), having mild mood disturbance (BDI score 11-16), having moderate depression (BDI score 17-30), or having severe depression (BDI score $>30$ ). The patients filled the BDI questionnaire themselves or it was read out to them in case of poor vision or if they were illiterate. BDI was chosen since this has been the most used and validated score among ESRD and PD patients ${ }^{[3,9]}$. The baseline demographic profile of these patients at the time of BDI administration was recorded. The duration of dialysis, urine output, presence of co-morbidities like diabetes mellitus (DM) and coronary artery disease (CAD), were also recorded along with bio-chemical profile including blood urea, serum creatinine, serum albumin and hemoglobin.

\section{Statistical analysis}

The statistical analysis was performed using Stata version 8 (Texas, United States). The results were expressed as mean \pm SD wherever appropriate. Univariate and multivariate regression analysis was done to calculate adjusted odds ratio in depressed compared non-depressed patients.

\section{RESULTS}

Of the 89 patients eligible for the study, 82 patients consented for the same $(92.1 \%)$. Baseline profile of the 82 patients who completed BDI is shown in Table 1. The mean age of the study population was $51.5 \pm 11.5$ years. In the study population there were $64.6 \%$ males and $34 \%$ diabetics. The mean duration on PD was $47.6 \pm 21.1$ months (range 7-105 months). The mean BDI score of the study population was $19.1 .19(23.2 \%)$ patients reported no depression (BDI score $\leqslant 10), 13(15.9 \%)$ reported having mild mood disturbance (BDI score 11-16), while 50 (61\%) reported having depression having BDI scores of $\geqslant 17.10$ patients $(12.2 \%)$ had severe depression (BDI score $>30$ ). All the patients detected having severe depressive symptoms were encouraged to undergo a formal psychiatric evaluation. However, only 4 patients opted for same and only 2 subsequently had a regular psychiatry follow-up.

Table 2 shows the odds ratio (OR) of various parameters between depressed and non-depressed patients. On univariate analysis (unadjusted OR) depressed patients were found to have lower body mass index (OR $0.36, P$ value 0.03 ), blood urea (OR $0.28, P$ value 0.01 ), serum alkaline phosphatase (OR $0.32, P$ value 0.02 ), total serum protein (OR $0.33, P$ value 0.02 ), serum albumin (OR 0.12 , $P$ value $>0.01)$ and serum uric acid (OR $0.34, P$ value 0.02$)$. After multivariate regression analysis (adjusted OR), parameters that were still found to be lower in depressed patients were blood urea (OR 0.19, confidence interval 0.06-0.65), serum albumin (OR 0.15, confidence interval 0.04-0.51) and serum alkaline phosphatase (OR 0.15 , confidence interval 0.04-0.57).

\section{DISCUSSION}

Depression is ranked fourth among disabling diseases affecting people worldwide ${ }^{[10]}$ and is the most common psychological problem observed in patients with $\mathrm{ESRD}^{[1-4]}$. PD being a domiciliary therapy requires patient to organize their own care and therefore it can be expected that depression would play a crucial role in influencing the complication rate and outcome associated with this therapy. Studies from the United States have reported incidence of depressive symptoms in PD population to be around $50 \% \%^{[7,9]}$. However, prevalence of depression in PD patients has shown a wide variation depending upon the criteria used and patient population studied, with Kim et $a l^{[8]}$ reporting a prevalence of $75 \%$ in their Korean PD population. In our study among Indian PD patients, we found a high prevalence of self-reported depressive symptoms among our PD patients $(61 \%)$, with around $12 \%$ reporting severe depression and a mean BDI score of 19.1. Difference in social and economic background, besides race and ethnicity could be the factors contributing to this increased incidence of depression among our patients as compared to other western studies. We also found a marked reluctance in patients to undergo a regular psychiatric opinion and follow-up with only $40 \%$ of severely depressed patients agreeing for a formal psychiatric evaluation and only $20 \%$ subsequently having a regular follow-up. Wuerth et $a l^{[9]}$ similarly found that $55 \%$ of their depressed PD patients refused further psychiatric evaluation and subsequently $32 \%$ discontinued therapy after a brief followup. Reluctance for anti-depressant therapy and high drop-out rates have also been noted in depressed patients without major medical 


\begin{tabular}{|c|c|c|c|c|c|}
\hline Variables & $\mathrm{BDI} \leqslant 16$ & BDI $>16$ & $P$-value & Unadjusted OR (95\% CI) & Adjusted OR (95\% CI) \\
\hline \multicolumn{6}{|c|}{ Age (years) } \\
\hline$\leqslant 30$ & 4 & 2 & 0.35 & 1 & \\
\hline $31-50$ & 11 & 19 & & $3.45(0.54,22.03)$ & \\
\hline$>50$ & 17 & 29 & & $3.41(0.56,20.64)$ & \\
\hline \multicolumn{6}{|l|}{ Gender } \\
\hline Male & 19 & 34 & 0.43 & 1 & \\
\hline Female & 13 & 16 & & $0.69(0.27,1.73)$ & \\
\hline \multicolumn{6}{|c|}{ Literacy Status } \\
\hline Illiterate & 13 & 30 & 0.09 & 1 & \\
\hline Literate & 19 & 20 & & $0.46(0.18,1.13$ & \\
\hline \multicolumn{6}{|c|}{ Duration on PD (months) } \\
\hline$\leqslant 42$ & 18 & 19 & 0.11 & 1 & \\
\hline$>42$ & 14 & 31 & & $2.10(0.85,5.17)$ & \\
\hline \multicolumn{6}{|c|}{ Urine Output (ml/day) } \\
\hline$>300$ & 17 & 20 & 0.14 & 1 & \\
\hline$<300$ & 15 & 30 & & $2.1(0.84,5.3)$ & \\
\hline \multicolumn{6}{|c|}{ Presence of Cardiovascular Disease } \\
\hline Present & 9 & 9 & 0.28 & 1 & \\
\hline Absent & 23 & 41 & & $1.78(0.62,5.12)$ & \\
\hline \multicolumn{6}{|c|}{ Body Mass Index } \\
\hline$\leqslant 23$ & 13 & 30 & 0.03 & 1 & \\
\hline$>23$ & 18 & 15 & & $0.36(0.14,0.93)$ & \\
\hline \multicolumn{6}{|c|}{ Hemoglobin (gm\%) } \\
\hline$\leqslant 9$ & 16 & 29 & 0.48 & 1 & \\
\hline$>9$ & 16 & 21 & & $0.72(0.30,1.77)$ & \\
\hline \multicolumn{6}{|c|}{ Blood Urea (mg\%) } \\
\hline$\leqslant 121$ & 12 & 34 & 0.01 & 1 & 1 \\
\hline$>121$ & 20 & 16 & & $0.28(0.11,0.72)$ & $0.19(0.06,0.65)$ \\
\hline \multicolumn{6}{|c|}{ Serum Creatinine $(\mathrm{mg} \%)$} \\
\hline$\leqslant 7$ & 27 & 41 & 0.78 & 1 & \\
\hline$>7$ & 5 & 9 & & $1.19(0.36,3.92)$ & \\
\hline \multicolumn{6}{|c|}{ Serum Alkaline Phosphatase (IU/dl) } \\
\hline$\leqslant 199$ & 18 & 40 & 0.02 & 1 & 1 \\
\hline$>199$ & 14 & 10 & & $0.32(0.12,0.86)$ & $0.15(0.04,0.57)$ \\
\hline \multicolumn{6}{|c|}{ Total serum protein $(\mathrm{g} / \mathrm{dl})$} \\
\hline$\leqslant 6.5$ & 8 & 25 & 0.02 & 1 & \\
\hline$>6.5$ & 24 & 25 & & $0.33(0.13,0.88)$ & \\
\hline \multicolumn{6}{|c|}{ Serum albumin (g/dl) } \\
\hline$\leqslant 3.5$ & 5 & 30 & $>0.01$ & 1 & 1 \\
\hline$>3.5$ & 27 & 20 & & $0.12(0.04,0.37)$ & $0.14(0.04,0.51)$ \\
\hline \multicolumn{6}{|c|}{ Serum Cholesterol (mg/dl) } \\
\hline$\leqslant 173$ & 19 & 35 & 0.32 & 1 & \\
\hline$>173$ & 13 & 15 & & $0.63(0.25,1.59)$ & \\
\hline \multicolumn{6}{|c|}{ Serum LDL/HDL ratio } \\
\hline$\leqslant 2.6$ & 23 & 37 & 0.83 & 1 & \\
\hline$>2.6$ & 9 & 17 & & $0.90(0.33,2.43)$ & \\
\hline \multicolumn{6}{|c|}{ Serum Calcium $(\mathrm{mg} \%)$} \\
\hline$\leq 8$ & 12 & 18 & 0.89 & 1 & \\
\hline$>8$ & 20 & 32 & & $1.07(0.42,2.68)$ & \\
\hline \multicolumn{6}{|c|}{ Serum Phosphate (mg\%) } \\
\hline$\leqslant 5$ & 21 & 36 & 0.54 & 1 & \\
\hline$>5$ & 11 & 14 & & $0.74(0.28,1.93)$ & \\
\hline \multicolumn{6}{|c|}{ Serum Uric Acid (mg\%) } \\
\hline$\leqslant 5$ & 15 & 36 & 0.02 & 1 & \\
\hline$>5$ & 17 & 14 & & $0.34(0.13,0.87)$ & \\
\hline
\end{tabular}

illness $^{[11]}$. This can partly explain the initial reluctance and high drop out rate in our set of patients who in addition to depression have complex medial illness and therapy. We could not find a significant difference between the demographic and socio- economic status of the depressed as compared to non-depressed patients. Most other studies have not found any demographic factor to be significantly associated with depression ${ }^{[7,9]}$, while Einwohner et $a l^{[6]}$ have found increasing age as a significant factor affecting depression. Of the initial medical profile we found that depression did not correlate with duration on PD, residual urine output, and presence co-morbidities like diabetes and cardiovascular disease (CAD). Among the dialysis patients the association between depression and co-morbidities like DM, CAD and PVD is not certain. Some authors have found the increasing co-morbidity profile to be positively correlated with depression $^{[6,7]}$, while others have found no significant correlation between the two ${ }^{[9]}$. We found that depressed patients had lower dietary protein intake as evidenced by lower blood urea and serum albumin in these patients. The association between depression and nutritional parameters in dialysis patients is more consistent. Recent studies from Turkey have also linked depression in dialysis 
patients (both HD and PD) with a decreased hemoglobin and serum albumin and increased C-reactive protein $(\mathrm{CRP})^{[12,13]}$. Another earlier study in Korean HD patients also noted that depression was closely related to the nutritional status ${ }^{[14]}$. Friend et al have looked at link between depression and serum albumin ${ }^{[15]}$. They in their 72-dialysis patients (32 HD and $40 \mathrm{PD}$ ) noted that depressive symptoms preceded the fall in serum albumin, while there was no association between initial serum albumin level and development of depression. Koo et a ${ }^{[16]}$ have recently shown an improvement in nutritional status in HD patients subsequent to successful completion of anti-depressant treatment for 8 weeks. These studies suggest that depression causes malnutrition. The biological mechanisms by which depression might lead to malnutrition and lower albumin levels are not entirely clear. Depression is commonly associated with decreased food intake, which can aggravate malnutrition in chronic dialysis patients ${ }^{[17]}$. There also is evidence that major depression is accompanied by activation of the inflammatory response system, and pro-inflammatory cytokines may have a role in causation of depression ${ }^{[18,19]}$. Thus pro-inflammatory cytokines can be a common link between depression and malnutrition in dialysis patients.

Our study however has few limitations. It's a single center, crosssectional study with a small sample size; therefore the results need to be confirmed by larger multi-centric study. Depressive symptoms in dialysis patients may wax and wane with time and hence single point assessment of depressive symptoms might not be representative of subsequent events. However, the high prevalence of depression noted in our study, indicates an urgent need to look at depression in our PD population. We also have not looked at the effect of antidepressant therapy if any on outcome measures. Also being a crosssectional study we cannot assign any cause effect relationship from our study.

To conclude, our study suggests a high prevalence of depression (61\%) among Indian PD patients, with depressed patients having lower serum urea and albumin indicating poorer dietary protein intake and malnutrition. These results advocate for inclusion of screening for depression as a part of routine care provided to PD patients. Further studies are however required to look at the effect of regular screening for depression and its treatment on long term outcome and infectious complications.

\section{CONFLICT OF INTERESTS}

Declaration of interest: The authors report no conflicts of interest. The authors alone are responsible for the content and writing of the paper.

Compliance with ethical standards: The institutional ethics committee approved the study and written informed consent was obtained from all the study subjects.

\section{REFERENCES}

1. Finkelstein FO, Finkelstein SH. Psychological adaptation and quality of life of the patient with end-stage renal disease. In: Brown E, Parfrey P, editors. Complications of Long Term Dialy- sis. Oxford: Oxford University Press, 1999: 168-187.

2. Kimmel PL. Psychosocial factors in dialysis patients. Kidney Int 2001; 59: 1599-1613.

3. Finkelstein FO, Finkelstein SH. Depression in chronic dialysis patients: Assessment and treatment. Nephrol Dial Transplant 2000; 15: 1911-1913.

4. Watnick S, Kirwin P, Mahnensmith R, Concato J. The prevalence and treatment of depression among patients starting dialysis. $\mathrm{Am} \mathrm{J}$ Kidney Dis 2003; 41: 105-110.

5. Kimmel PL, Weihs KL, Peterson RA. Survival in hemodialysis patients: the role of depression. J Am Soc Nephrol 1993; 4: 12-27

6. Einwohner R, Bernardini J, Fried L, Piraino B. The effect of depressive symptoms on survival in peritoneal dialysis patients. Perit Dial Int 2004; 24: 256-263.

7. Troidle L, Watnick S, Wuerth DB, Gorban-Brennan N, Kliger AS, Finkelstein FO. Depression and its association with peritonitis in long-term peritoneal dialysis patients. Am J Kidney Dis 2003; 42: 350-354.

8. Kim JA, Lee YK, Huh WS, Kim YG, Kim DJ, Oh HY, Kang SA, Kim Moon YH, Kim HW, Kim JH. Analysis of depression in continuous ambulatory peritoneal dialysis patients. $J$ Korean Med Sci 2002; 17: 790-794.

9. Wuerth D, Finkelstein SH, Ciarcia J, Peterson RA, Kliger AS, Finkelstein FO. Identification and treatment of depression in a cohort of patients maintained on chronic peritoneal dialysis. Am J Kidney Dis 2001; 37: 1011-1017.

10. Murray CJ, Lopez AD. Alternative projections of mortality and disability by cause, 1990-2020: Global Burden of Disease Study. Lancet 1997; 349: 1498-1504.

11. Keller MB, McCullough JP, Klein DN, Arnow B, Dunner DL, Gelenberg AJ et al. A comparison of nefazodone, the cognitive behavioral-analysis system of psychotherapy and their combination for the treatment of chronic depression. N Engl J Med 2000; 342: $1462-1470$.

12. Dogan E, Erkoc R, Eryonucu B, Sayarlioglu H, Agargun MY. Relation between depression, some laboratory parameters, and quality of life in hemodialysis patients. Ren Fail 2005; 27: 695-699.

13. Kalender B, Corapcioglu Ozdemir A, Koroglu G. Association of depression with markers of nutrition and inflammation in chronic kidney disease and end-stage renal disease. Nephron Clin Pract 2005; 102: c115-c121

14. Koo JR, Yoon J, Kim SG, Lee YK, Oh KH, Kim GH, et al. Association of depression with malnutrition in chronic hemodialysis patients. Am J Kidney Dis 2003; 41: 1037-1042

15. Friend R, Hatchett L, Wadhwa NK, Suh H. Serum albumin and depression in end-stage renal disease. Adv Perit Dial 1997; 13: 155-157.

16. Koo JR, Yoon JY, Joo MH, Lee HS, Oh JE, Kim SJ et al. Treatment of depression and effect of antidepression treatment on nutritional status in chronic hemodialysis patients. Am J Med Sci 2005; 32: 1-5.

17. Blumenkrantz MJ. Nutrition. In: Daurgidas JT, Igns TS, editors. Handbook of dialysis. 2nd ed. Boston: Little Brown, 1994: 374400.

18. Maes M. Major depression and activation of the inflammatory response system. Adv Exp Med Biol 1999; 461: 25-46.

19. Seidel A, Arolt V, Hunstiger M, Rink L, Behnisch A, Krichner H. Cytokine production and serum protein in depression. Scand J Immunol 1995; 41: 534-538. 